\title{
A responsabilidade social em clubes de futebol como estratégia de valorização da marca: o caso do Santa Cruz futebol clube
}

A Responsabilidade Social vem promovendo um profundo interesse na gestão do mundo empresarial, mas pouquíssimas vezes foi avaliada em investigações no campo da gestão dos clubes de futebol. Tendo em vista o verdadeiro papel social que suscita a gestão de Responsabilidade Social Corporativa (RSC) dos clubes de futebol, a investigação tem como premissa conhecer a realidade pragmática da gestão de RSC no desporto e no futebol em específico, bem como sua observação e análise, das práticas e ações socioambientais desenvolvidas pelos clubes junto aos stakeholders e entorno meio ambiental - usadas para promover a imagem institucional das equipes, para posteriormente propor sua implementação no contexto do Santa Cruz Futebol Clube. Este trabalho objetivou analisar como o Santa Cruz Futebol Clube pode aderir ao modelo Ethos de Responsabilidade Social, a fim de se estabelecer uma nova postura diante dos stakeholders, no sentido de melhorar a gestão e imagem corporativa do clube diante das novas perspectivas do mercado. Este artigo se caracteriza inicialmente por ser uma pesquisa bibliográfica. Quanto a natureza da pesquisa, caracteriza-se como aplicada, uma vez que buscou apresentar aos stakeholders a implantação de indicadores relacionados à responsabilidade social do clube a fim de melhoria da imagem corporativa. Diante do detalhamento histórico da evolução das várias visões a respeito das concepções e adequação das teorias relacionadas a RS, foi possível compreender que o discurso está de fato em conformidade com o relacionamento recíproco entre as atividades principais da organização com as carências prementes da sociedade, de maneira que as ações neste sentido ocasionem reflexos positivos, seja para os negócios, como também para o desenvolvimento comunitário. A troca de valores entre o clube e os indivíduos aparenta ser de fato o fator preponderante para que práticas nesta esfera obtenham um impacto perene, ou seja, estejam introduzidas na visão atual de governança estratégica de forma definitiva, e não apenas eventualmente. Pode-se concluir, portanto que a adoção de Responsabilidade Social Corporativa pode influenciar de forma significativa e expressiva o clube e os stakeholders associados ao Santa Cruz Futebol Clube.

Palavras-chave: Responsabilidade Social Corporativa; Modelos de RSC; Modelo Ethos; Clubes de Futebol; Santa Cruz Futebol Clube.

\section{Social responsibility in soccer clubs as a brand valuation strategy: the case of the Santa Cruz soccer club}

\begin{abstract}
Social Responsibility is promoting an interest in the business world, but job opportunities have been promoted in the business field. The social network social network, RSC, Social Marketing Social Responsibilty is promoting an interest in the business world, but job opportunities have been promoted in the business field. The social network social network, RSC, social Marketing and social actions to the age of the metering to mission from the community in the United States of Santa Cruz Football Club. This work aimed to be evaluated as the Santa Cruz Futebol Clube and social actions to the age of the metering to mission from the community in the United States of Santa Cruz Football Club. This work aimed to be evaluated as the Santa Cruz Futebol Clube
can join the Ethos model of Social Responsibility, in order to establish a new posture before the stakeholders, without the sense of improving the corporate management of the program in can join the Ethos model of Social Responsibility, in order to establish a new posture before the stakeholders, without the sense of improving the corporate management of the program in
face of the new perspectives of the market. This article is characterized by being a bibliographical research. As the nature of the research, as it applies, it sought to present to stakeholders a face of the new perspectives of the market. This article is characterized by being a bibliographical research. As the nature of the research, as it applies, it sought to present to stakeholders
planning task related to the social responsibility of the club. In view of the historical detail of the evolution of the various visions regarding the conceptions and adequations of the theories related to RS, it was the emergency that aims to be in conformity with the reciprocal relationship between the main entities of the organization as pressing characters of society, have positive impacts, both for business and for community development. The exchange of values between the club and the individuals has proved to be a preponderant factor for the progress of obtaining a perennial effect, that is, desires were introduced in strategic governance in a definitive way, and not only eventually. It can be completed, therefore, that an admission of Corporate Social Responsibility can significantly and expressively influence the club and stakeholders associated with Santa Cruz Futebol Clube.
\end{abstract}

Keywords: Corporate Social Responsibility; CSR Models; Ethos Model; Football Clubs; Santa Cruz Futebol Clube.

Topic: Responsabilidade Socioambiental Corporativa

Reviewed anonymously in the process of blind peer

Plácido Fernandes Caluete Neto (it)

Faculdade de Arquitetura e Urbanismo de Pernambuco, Brasil

http://lattes.cnpq.br/3401501999562068

http://orcid.org/0000-0001-7006-2344

placidofernandes@gmail.com

Andressa Ribeiro de Queiroz (iD

Universidade Federal de Pernambuco, Brasil

http://lattes.cnpq.br/2200656120877897

http://orcid.org/0000-0002-6413-0838

arqueirozconsult@gmail.com

\section{Carlos Eduardo Silva (iD}

Companhia Brasileira de Produção Científica, Brasil

http://lattes.cnpq.br/3700554054159220

http://orcid.org/0000-0001-8358-0263

carlos.eduardo@cbpciencia.com.br

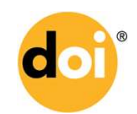

DOI: 10.6008/CBPC2179-684X.2019.004.0009
Received: 15/10/2019

Approved: 21/12/2019
Referencing this:

CALUETE NETO, P. F.; QUEIROZ, A. R.; SILVA, C. E.. A responsabilidade social em clubes de futebol como estratégia de valorização da marca: o caso do santa cruz futebol clube. Revista Brasileira de Administração Científica, v.10, n.4, p.125-144, 2019. DOI: http://doi.org/10.6008/CBPC2179-684X.2019.004.0009 


\section{INTRODUÇÃO}

Segundo Dantas et al. (2011) entre os esportes, o futebol é o que mais atrai a atenção do público em todo o mundo, devido as grandes contratações, contratos de patrocínios milionários, arrecadação de bilheteria etc. Esse esporte envolve milhares de dólares e é alvo de discussões tanto na mídia esportiva, quanto na população em geral. Silva (2005) afirma que o futebol movimenta cerca de US\$ 1 trilhão por ano. Essa quantia está associada ao fato de que o mercado do futebol é movido mais pelo lado da paixão do que o da razão, já que a maioria dos torcedores não se importam com os gastos e arrecadação de receitas e sim com os títulos e as contratações de jogadores.

Segundo Fernandes (2000), o Brasil, pela sua miscigenação, por sua extensão territorial e pela sua grande população, pode ser considerada uma nação esportiva em potencial. O futebol, neste contexto, é uma das principais fontes de identidade da nação e representa o primeiro dentre os esportes praticados no país, fazendo parte do cotidiano brasileiro, quer seja no seu convívio social, quer seja no profissional.

Diferente dos outros setores da economia, o mercado do desporto se comportava de forma bastante peculiar. Existia um risco considerável no setor, no sentido de saber se os investimentos constantemente feitos em contratações e modificações se transformariam em sucesso. Sabe-se que, historicamente, houveram diversos exemplos de equipes organizadas com enormes investimentos e que não tiveram seus objetivos alcançados. Nesse sentido, os gestores das agremiações esportivas devem se adequar as premissas deste mercado singular. Como afirma Dantas et al. (2011),

Primeiramente, os investimentos devem estar de acordo com as condições financeiras do clube. Depois, devem-se achar maneiras para, em caso de o clube não estar bem esportivamente, mesmo com jogadores de qualidade, atrair novos recursos, com ações de marketing, exploração de imagem de algum jogador e etc..

Um dos temas mais recorrentes nas discussões cotidianas do mundo do futebol é a deficiência na gestão dos clubes brasileiros, segundo os dados dos balanços das agremiações de 2014, a dívida dos 12 grandes clubes brasileiros superou, pela primeira vez, a casa dos R\$ 5 bilhões. Para Máximo et al. (2006), os clubes de futebol são instituições que, embora o volume financeiro circulante seja grande, geralmente ainda são estruturas deficitárias, administrativamente ineficientes. Essas organizações, em especial no Brasil, são reconhecidas, historicamente, por sua má gestão e pela falta de credibilidade das pessoas que são responsáveis por sua administração.

Perruci (2006) revela melhorias na gestão esportiva ao afirmar que, a partir da década de 80, especialmente, após a consolidação do capitalismo como sistema político e econômico hegemônico em conjunto com a evolução da mídia e meios de transmissão eletrônicos, foi agregado ao esporte o paradigma mercadológico, com possibilidades ilimitadas do ponto de vista econômico.

Desde sua fundação, em 1914, o Santa Cruz Futebol Clube ficou conhecido ao longo do tempo como uma das mais tradicionais agremiações do Nordeste, tendo seu auge nas décadas de 1960 e 1970, quando chegou a estar entre os melhores clubes do país em competições nacionais, quando disputou com equidade com clubes dos eixos Sul e Sudeste, numa época em que os negócios provenientes do futebol ainda não envolviam cifras tão altas como nos dias atuais. 
Com a modernização do futebol, especialmente após a criação do então Clube dos 13 e, posteriormente, com a definição das cotas de patrocínio da TV, as receitas provindas das bilheterias nos dias de jogos começaram a não ser mais suficientes para manter o clube, para arcar com seus compromissos e ainda montar planteis competitivos para disputar de forma igualitária com os clubes que dispunham de vultosas verbas. Se para os clubes pertencentes a esse grupo, o processo de modernização tornar-se-ia demorado, para o Santa Cruz então, tal processo se tornou dificultoso ao longo dos anos.

A 'Lei Pelé', implementada em 1998, ao estabelecer o conceito clube-empresa e o futebol como negócio, fez com que a modalidade passasse a ser responsável pela principal fonte de receita e ser o principal elemento de formatação e manutenção de uma imagem forte da marca, hoje o maior patrimônio dos clubes. No entanto, o Santa Cruz custou a se adequar à essa nova realidade, uma vez que, mantinha sua gestão de forma arcaica, ainda dependia basicamente das receitas de bilheterias e das verbas patrimoniais provindas dos aluguéis de cadeiras e camarotes. Para agravar ainda mais a situação desfavorável de atraso do clube, sobretudo, no cenário nacional, é possível atribuir à gradativa redução do quadro de sócios ao longo dos anos - em sua boa parte - as más campanhas e administrações que promoveram desequilíbrio nas finanças e falta de transparência da gestão, gerando ainda mais passivos para a agremiação, o que naturalmente incidiu na desvalorização da marca, transmitindo uma imagem de descrédito do clube para com seus associados, assim como para patrocinadores, stakeholders, demais parceiros e sociedade como um todo.

Com a tendência cada vez maior dos clubes de futebol tornarem-se empresas, entende-se, portanto, que o Planejamento estratégico deve estar presente em todos os setores do clube para uma melhor profissionalização. Agremiações que acumulam dívidas ao longo das gestões tendem a comprometer seu futuro e ficarem estagnadas perante os demais times, sobretudo, quando se trata dos que não dispõem das grandes cotas televisivas, que tendem a criar um 'abismo' cada vez maior entre os clubes. Para Ribeiro (2014), os patrocinadores dos clubes de futebol têm papel fundamental no que diz respeito aos salários e contratações dos jogadores, já que os custos de recursos humanos representam a maior parte dos custos dos times.

O tema da Responsabilidade Social Corporativa (RSC) é facilmente percebido em diversas organizações. No desporto o assunto não tem sido diferente, vindo a se tornar um campo de preocupação e atuação importante dos entes deste setor de atividade. A Responsabilidade Socioambiental pode ser entendida como "atividades voluntárias do clube, demonstrando a inclusão de preocupações ambientais e sociais nas operações comerciais quanto às interações com os stakeholders" (VAN MARREWIJK, 2003).

A RSC sugere que as empresas têm responsabilidades perante todos os seus intervenientes, quer diretos quer indiretos, tornando assim mais ampla a sua abrangência em relação à sociedade. As evidências referentes às empresas responsáveis e da sua consequente performance económica, não são mutuamente exclusivas, uma vez que podem sempre reforçar a sua posição, fazendo o bem enquanto se faz bem, de modo que a RSC acompanhe toda a atividade do clube, projetando assim o bem-fazer. Os intervenientes contêm toda a estrutura das instituições políticas e a estratégia dos grupos de interesse são um importante fator na explicação do impacte das organizações não governamentais (ONG) no processo de decisão e na formação de preferências. (DOH et al., 2006)

A RSC tem se constituído como um fator de competitividade para o mundo dos negócios e vem sendo 
utilizada por diversas empresas como um diferencial diante de seus adversários. Todavia, para que determinada organização possa ser definida como socialmente responsável é necessário vincular sua marca a uma causa ou à preservação do meio ambiente, se tornando imprescindível um investimento constante e eficaz nas relações com seus stakeholders. Nesse cenário, o tema recebe cada vez mais importância, caracterizando-se como componente de competitividade entre as empresas e com os clubes de futebol não é diferente.

Caetano (2008) afirma que as empresas entendidas como agentes ativos e determinantes das atividades econômicas da sociedade têm uma grande responsabilidade no seu desenvolvimento, cabendo a essas possuir um especial cuidado no que diz respeito à sua conduta, imagem e posicionamento na dimensão social em que se inserem. Para o autor, "a responsabilidade social corporativa influencia, positivamente, a performance dos clubes de futebol, na medida em que reforça a visibilidade, reconhecimento, imagem de marca e credibilidade" (CAETANO, 2008).

Existem diversos modelos de avaliação para as organizações alinhados com a responsabilidade social. Esses modelos são adotados em vários países e expressam um conjunto de indicadores que não apenas acompanham e controlam as práticas e estratégias empresariais para obter competitividade e lucratividade, mas são capazes de apontar as fragilidades e necessidades das iniciativas de responsabilidade social (RABELO et al. 2011).

No Brasil, a busca de uma responsabilidade social transparente e alinhada com fornecedores e cliente fez o Instituto Ethos lançar o sistema dos Indicadores Ethos. Para o instituto, o clube 'socialmente responsável' é aquela que possui a capacidade de ouvir os interesses das diferentes partes (acionistas, funcionários, prestadores de serviço, fornecedores, consumidores, comunidade, governo e meio ambiente) e conseguir incorporá-los ao planeamento de suas atividades, buscando atender às demandas de todos e não apenas dos acionistas ou proprietários. Para o instituto, a Responsabilidade Social Empresarial (RSE) implica em práticas de diálogo e engajamento do clube com todos os públicos ligados a ela, a partir de um relacionamento ético e transparente, ainda que, a prática desses métodos seja um desafio para as organizações, diversas delas têm obtido resultados expressivos nesse sentido.

Esses indicadores permitem também às organizações acompanharem a gestão da responsabilidade social de seus fornecedores e clientes dando credibilidade e confiança a RSE. Através desse modelo, os fornecedores e clientes, ao preencher o questionário dos Indicadores, podem autorizar, via sistema, que as empresas com as quais eles mantêm contrato de fornecimento tenham acesso a seus dados cadastrais. Essa iniciativa visa estimular e facilitar os processos de gestão socialmente responsável nas cadeias de valor das empresas, já comprometidas com o tema, e que esperam ampliar os resultados de suas ações por meio de seus fornecedores e clientes.

Diante desse contexto, se faz necessário analisar como o Santa Cruz Futebol Clube pode aderir a um modelo de RSC capaz de auxiliar o clube em questão, a fim de se estabelecer uma nova postura diante da sociedade e, sobretudo, diante dos atores envolvidos, no sentido de melhorar a gestão e imagem corporativa do clube diante das novas perspectivas do mercado para se tornar conceituado e competitivo no cenário 
nacional.

Para atingir os objetivos pretendidos, foi desenvolvida a seguinte questão: Em que medida a adoção de RSC pode influenciar na performance dos clubes de futebol, em especial no o Santa Cruz Futebol Clube? Propõe-se, para tanto, através deste trabalho, descrever o modelo de indicadores de Responsabilidade Socioambiental Corporativa do Instituto Ethos alinhado ao time analisado e analisar como o time pode adota o modelo em questão, pois se acredita que tal medida seja de relevante importância para que o clube em questão possa analisar e mensurar seu desempenho perante o público.

\section{METODOLOGIA}

Este artigo se caracteriza inicialmente por ser uma pesquisa bibliográfica que tem como objetivo o fornecimento de informações a respeito de assuntos relevantes com relação ao tema apresentado, explicando-o e discutindo-o com base em autores e referências já publicadas em livros, revistas, periódicos entre outros (GIL, 2001).

Quanto a natureza da pesquisa, caracteriza-se como aplicada, uma vez que buscou apresentar aos stakeholders a implantação de indicadores relacionados à responsabilidade social do clube a fim de melhoria da imagem corporativa. De acordo com Cervo et al. (1996) neste tipo de estudo "[...] o investigador é movido pela necessidade de contribuir para fins práticos mais ou menos imediatos, buscando soluções para problemas concretos".

Com relação ao objetivo, classifica-se como descritiva, pois tende a analisar os aspectos que estão associados a implantação da RSC em um time específico. De acordo com Gil (2001), as pesquisas que possuem como objetivo principal a descrição das características de determinado fenômeno ou população, ou que estabelecem relações entre variáveis no objeto de estudo analisado podem ser denominadas de pesquisas descritivas. Portanto, a abordagem utilizada na pesquisa foi qualitativa já que os indicadores Ethos foram descritos se alinhando as peculiaridades do Clube analisado.

\section{DISCUSSÃO TEÓRICA}

Com o intuito de analisar como o Santa Cruz Futebol Clube poderia adotar as práticas de Responsabilidade Social segundo os indicadores Ethos, foi feita uma análise, nesse trabalho, com o objetivo de verificar a adequação, vantagens, benefícios e melhorias que o time analisado teria se utilizasse tal modelo de responsabilidade social.

\section{Dimensão valores, transparência e governança}

Analisando a primeira dimensão denominada 'Valores, transparência e governança' está se divide em 'auto regulação da conduta' e 'relações transparentes com a sociedade'. E são avaliadas segundo alguns indicadores que serão discutidos a seguir. Para a 'autorregularão da conduta' o clube precisa expor publicamente seus compromissos éticos por meio de material institucional, pela internet ou de outra maneira adequada às suas partes interessadas 
É preciso também apresentar um código de conduta e/ou a declaração de valores da organização que contemple as partes interessadas: empregados, fornecedores, meio ambiente, consumidores/clientes, comunidade, governo e acionistas minoritários; devendo constar também proibição expressa da utilização de práticas ilegais (como suborno, corrupção, extorsão, propina e caixa dois) para obtenção de vantagens comerciais e compromisso de ética na gestão das informações privilegiadas ou de caráter privado obtidas durante os processos do clube em sua interação com seus diversos públicos (clientes, empregados, fornecedores etc.). Bem como possuir o compromisso de transparência e veracidade das informações prestadas a todas as partes interessadas e os valores da organização sobre: $\mathrm{O}$ cumprimento das leis e pagamento de tributos; Concussão, pagamentos ou recebimentos questionáveis; Regras explícitas no relacionamento com agentes públicos; Conflito de interesses; Doações; Corrupção ativa e passiva; Improbidade administrativa; Fraude em concorrência pública; Limites das atividades e contribuições políticas; Relações com a comunidade; Nepotismo; e Prevenção e tratamento de fraudes.

O clube precisa possuir comitê, conselho ou responsável(is) formal(is) por questões éticas reconhecido(s) internamente e externamente, bem como estimular a coerência entre os valores e princípios éticos da organização e a atitude individual de seus empregados. Os indicadores também avaliam se o clube vincula expressamente a atuação das assessorias jurídica e contábil ao código de conduta/declaração de princípios, além de atender toda a legislação em vigor para seu exercício e estar em dia com todos os tributos, e apresentar os procedimentos para que todos os seus empregados conheçam as leis a que estão submetidos, tanto as que se referem às atividades profissionais quanto as que os beneficiam, para que possam cumpri-las integralmente.

Quanto ao indicador de 'Enraizamento na cultura organizacional', um ponto relevante são as questões éticas que devem ser abordadas em pesquisas de clima organizacional, por avaliação 360 graus ou ferramentas similares. Nessa pesquisa, os empregados do clube precisam demonstrar familiaridade no seu dia a dia com os temas e pressupostos contemplados no código de conduta, aplicando-os espontaneamente.

Quanto ao indicador de 'governança corporativa' a alta direção do clube deve possuir conta com mecanismos ou sistemas formais para avaliação periódica dos seus integrantes, entendidos como os stakeholders. O clube precisa possuir estrutura que contempla um conselho de administração ou consultivo e uma auditoria externa independente, visando: Assegurar o controle da propriedade sobre a gestão; Prevenir/coibir abusos de poder de seus integrantes, fraudes por uso de informação privilegiada em benefício próprio ou atuação em conflito de interesses; e Desencorajar o suborno e outras práticas de corrupção, a criação de 'contabilidades paralelas' ou de contas secretas e a elaboração de documentos que não reflitam verdadeiramente as transações que reportam.

Para nomear membros do conselho de administração ou consultivo, o clube deve levar em consideração habilidades, conhecimentos, especialização e independência para orientar o direcionamento estratégico da organização, incluindo questões relativas a oportunidades e riscos ambientais e sociais, e monitorar a atuação dos gestores (diretoria). Esse quesito é de suma importância para a gestão financeira do clube, fortalecendo a transparência e a clareza nas receitas e despesas do clube. Nesse sentido, o clube 
deve utilizar estudos, pesquisas e o apoio de especialistas para melhor fundamentar a resolução de dilemas éticos, socioambientais e relativos a direitos humanos, incluindo aqui o respeito aos direitos humanos como critério formal em suas decisões de investimento e aquisição.

As orientações do modelo Ethos sugerem que as práticas trabalhistas do clube estejam em concordância com a declaração da Organização Internacional do Trabalho (OIT) sobre os princípios e direitos fundamentais no trabalho ou com os Princípios do Pacto Global ou em apoio aos Objetivos de Desenvolvimento do Milênio (ODM). Assim a visão do clube e sua estratégia irão contemplar as contribuições da organização no que se refere ao desenvolvimento sustentável. Quanto as relações com as 'concorrências', o clube deve apresentar as seguintes informações a respeito dos princípios em relação à concorrência leal e esses princípios devem constar no código de conduta e/ou na declaração de valores do clube.

O clube precisa expor publicamente, e com frequência, seus princípios em relação à concorrência (por exemplo, por meio de seu website, de material institucional, do relatório anual etc.) e possuir política de não utilização da demonstração dos defeitos ou deficiências dos produtos ou serviços dos concorrentes para promover seus produtos ou serviços. A política sobre concorrência desleal abrange a cadeia produtiva do clube e deve abordar os seguintes itens: Pirataria; Sonegação fiscal; Contrabando; Adulteração de produtos ou marcas e Falsificação de produtos.

Sabe-se que a falsificação de produtos é recorrente nos times de futebol, elencar esses prejuízos, dará ao time a real condição de como deve fortalecer sua política de vendas de produtos aos stakeholders. Quanto ao 'Diálogo e engajamento das partes interessadas', considerando seus impactos sobre distintos grupos da sociedade, o clube precisa dispor de práticas de conexão com seus stakeholders, para isso é preciso esclarecer se o clube está aberto a críticas de grupos ou partes interessadas sobre a natureza de seus processos, produtos ou serviços ou se tem política e/ou procedimentos de relacionamento para responder prontamente a qualquer sugestão, apelo, esforço ou demanda de suas partes interessadas.

Aqui se enquadra ouvidoria ou formas de comunicação com a comunidade interna e externa ao clube. Nesse sentido, é avaliado pelo Modelo ETHOS como se dá o processo de diálogo e engajamento das partes interessadas conta com indicadores de desempenho para monitoramento das relações e se o clube tem política para que os indicadores/dados/informações advindos do processo de diálogo e engajamento das partes interessadas sejam, comparáveis, confiáveis, relevantes e compreensíveis por suas partes interessadas.

Esses indicadores/dados/informações são utilizados no processo de planejamento geral do clube em discutir necessidades, melhorias, deficiências, ou seja, a partir de uma abertura democrática de participação dos stakeholders, abre-se um canal de comunicação e confiança que refletirá na fidelização de mais torcedores e de uma conexão maior as reais necessidades do clube.

A transparência na publicação desses indicadores/dados/informações deve constar no balanço social do clube. Sobre o assunto e em relação à elaboração de relatório sobre os aspectos econômicos, sociais e ambientais de suas atividades, o clube precisa informar sobre a situação econômico-financeira das suas atividades e esses dados devem ser auditados por terceiros. Precisam também ser auditados por terceiros 
independentes do clube as informações sobre aspectos sociais e ambientais das atividades do time.

No processo de elaboração do balanço social, o clube envolve deve envolver pelo menos quatro das seguintes partes interessadas: Comunidade; Público interno; Consumidores e clientes; Fornecedores; Governo; e Sociedade em geral (por meio, por exemplo, de contatos com organizações de defesa do meio ambiente, sindicatos, entidades voltadas para a saúde pública ou defesa dos direitos humanos etc.). Ao produzir o balanço social o clube deve levar em consideração os princípios de: Inclusão; Relevância e Materialidade; Abrangência; Equilíbrio; Comparabilidade; Exatidão; Periodicidade; Clareza e Confiabilidade.

\section{Dimensão público interno}

Na dimensão do 'público interna' o clube deve apresentar ações envolvendo o diálogo e participação, o respeito ao indivíduo e ao trabalho decente. Dentro do item Diálogo e participação existem os indicadores que discutem as relações com sindicatos a gestão Participativa. No item 'trabalho decente', discute-se assuntos relacionados à participação de empregados em sindicatos e ao relacionamento com seus representantes, assim o clube precisa fornecer informações que afetem os empregados em tempo hábil para que o sindicato e os empregados se posicionem e possuir acordo coletivo com o sindicato da categoria principal (seja dos colaboradores e dos jogadores) e disponibilizar informações básicas sobre direitos e deveres da categoria, tais como dissídio, contribuições sindicais etc.

$\mathrm{Na}$ 'Gestão Participativa', quanto ao envolvimento dos empregados na gestão, o clube precisa apresentar dados referentes a todos os integrantes de comissões de empregados - Comissão Interna de Prevenção de Acidentes (CIPA), Comissão de Conciliação Prévia (CCP), comissão de participação nos lucros e resultados etc. e se essas comissões são eleitas pelos empregados, sem interferência do clube. Se o clube possui políticas e mecanismos formais para ouvir, avaliar e acompanhar posturas, preocupações, sugestões e críticas dos empregados, com o objetivo de agregar novos aprendizados e conhecimentos e se o clube possui programa de incentivo e reconhecimento das sugestões dos empregados para melhoria dos processos internos.

No item 'Respeito ao indivíduo', é discutido o compromisso com o futuro das crianças, no tratamento da questão do combate ao trabalho infantil, o clube deve discutir com outros clubes ou apresentar propostas práticas para o combate ao trabalho infantil em seu setor (ou de maneira geral), apresentar se tem programa específico para contratação de aprendizes, aqui podendo-se incluir as escolinhas de base.

O clube precisa se conscientizar do seu papel social em relação aos aprendizes se oferece a eles boas condições de trabalho, aprendizado e desenvolvimento profissional e pessoal - com o devido acompanhamento, avaliação e orientação e, principalmente, ao encerrar o período referente ao programa de aprendizagem, se procura empregar os beneficiados na próprio clube; quando isso não é possível, busca colocação para eles em empresas ou organizações parceiras.

No quesito 'Compromisso com o desenvolvimento infantil', o clube deve considerar sua contribuição para o desenvolvimento infantil no país e o compromisso com os direitos das crianças, assim precisa dispor de informações se oferece programa específico para a saúde da mulher gestante, programa de orientação 
aos empregados sobre como se dá o desenvolvimento integral da criança por meio do fortalecimento das competências familiares; se faz acompanhamento periódico da cobertura vacinal, crescimento e desenvolvimento dos filhos dos empregados, solicitando e verificando a Caderneta de Saúde da Criança do Ministério da Saúde; se promove campanhas de imunização dos empregados e seus dependentes com vacinas não oferecidas pela rede pública de saúde (a antigripal, por exemplo); se faz acompanhamento da inclusão dos filhos dos empregados na escola, por meio de solicitação de comprovantes de matrícula (particularmente das crianças com deficiência); se possui política específica para os empregados que sejam pais ou responsáveis por crianças com deficiência, garantindo-lhes a possibilidade de acompanhar o desenvolvimento dos filhos de forma adequada; se contribui com os fundos geridos pelos conselhos dos direitos da criança e do adolescente, destinando para esse fim 1\% do Imposto de Renda devido; se estimula os empregados a destinar até $6 \%$ do Imposto de Renda devido para contribuir com os fundos geridos pelos conselhos dos direitos da criança e do adolescente; se estimula os fornecedores e empresas parceiras a destinar $1 \%$ do Imposto de Renda devido para contribuir com os fundos geridos pelos conselhos dos direitos da criança e do adolescente.

O aspecto de 'vantagens' também é solicitado pelo modelo ETHOS ao avaliar se o clube oferece para os empregados (mulheres e homens) de todos os níveis hierárquicos os seguintes benefícios: Plano de saúde familiar; Creche no local de trabalho ou por rede conveniada, conforme determina a lei; Flexibilidade de horário para empregados com filhos menores de 6 anos; e Auxílio para educação dos filhos. O clube precisa informar também se oferece aos trabalhadores terceirizados os mesmos benefícios de seus empregados registrados, aos trabalhadores comissionados se oferece os mesmos benefícios de seus empregados registrados e se possui políticas de acompanhamento do pós-parto, particularmente para identificação da depressão pós-parto ou facilita a utilização da flexibilidade de horário para amamentação, conforme a legislação em vigor.

É avaliado também qual o Percentual de filhos dos empregados matriculados em creche ( 0 a 3 anos); o percentual de filhos com deficiência dos empregados matriculados em creche ( 0 a 3 anos); o percentual de filhos com deficiência dos empregados matriculados em pré-escola (4 e 5 anos); o percentual de filhos dos empregados com vacinação em dia para a idade, conforme o calendário básico estabelecido pelo Ministério da Saúde dos empregados em regime CLT de contratação.

O nível de detalhamento do questionário levanta também dados sobre o total de empregados homens pais ou responsáveis por crianças de 0 a 5 anos de idade, o total de empregadas responsáveis (mães ou não) por crianças de 0 a 5 anos de idade, o total de empregadas cujo último filho recebeu amamentação exclusiva até os 4 meses de idade, o total de empregadas que tiveram horário flexível para amamentar o filho até 6 meses de idade, o total de dependentes de 0 a 5 anos filhos de mulheres empregadas, o total de dependentes de 0 a 5 anos filhos de mulheres empregadas com menos de quatro anos de escolaridade, 0 total de dependentes de 0 a 5 anos filhos de empregados homens, o total de dependentes de 0 a 5 anos filhos de empregados homens com menos de quatro anos de escolaridade, o total de dependentes menores de 1 ano de idade, o total de dependentes menores de 1 ano de idade vacinados com a tetravalente, o total 
de gestantes empregadas (ou dependentes de empregados), o total de gestantes empregadas (ou dependentes de empregados) em acompanhamento pré-natal, o total de dependentes de 4 e 5 anos de idade, o total de dependentes de 4 e 5 anos de idade matriculados em pré-escola. Esses mesmos dados são solicitados para os empregados terceirizados e os empregados autônomos ou comissionados.

No Indicador sobre a 'Valorização da diversidade', reconhecendo é avaliada a obrigação ética das empresas de combater todas as formas de discriminação negativa e de valorizar as oportunidades oferecidas pela riqueza da diversidade de nossa sociedade. Assim, o clube precisa dispor de uma política de valorização da diversidade e não-discriminação consta no código de conduta e/ou na declaração de valores do clube. Essa política contempla explicitamente: A questão étnico-racial; A questão de gênero; A questão de idade; A questão religiosa; A questão da orientação sexual; A questão da origem geográfica; A questão da classe social; A questão da deficiência; A questão da aparência física.

Nos processos e ferramentas de gestão de pessoas, o clube precisa inserir quesitos para monitorar a diversidade de seu quadro e possíveis desigualdades em relação aos segmentos em desvantagem, entre outras situações. Com relação à política de valorização da diversidade e não-discriminação o clube deve dispor de procedimentos formais para processos de seleção, admissão, promoção e mobilidade interna e demissão. Nessa política devem estar claramente previstos os mecanismos e canais formais para denúncia, encaminhamento, análise e apuração de fatos que envolvam possíveis casos de discriminação.

O clube precisa possuir um programa específico de contratação de pessoas com deficiência e atende rigorosamente a legislação de cotas de vagas para esse público e desse programa constar de uma política de valorização da diversidade e não-discriminação que deriva em procedimentos específicos para melhorar a qualificação e promover pessoas com deficiência ou em políticas para a contratação de pessoas com idade superior a 45 anos ou em procedimentos específicos que abordam a questão da faixa etária dos empregados ou em políticas específicas para empregados indígenas. Outra questão levantada é a acessibilidade. É avaliado se o clube promoveu ou está promovendo as adaptações necessárias para favorecer a acessibilidade, de acordo com a legislação em vigor. Há também o levantamento se o clube procura evitar a demissão de indivíduos com idade superior a 45 anos ou se oferece oportunidade de trabalho para exdetentos.

Quanto ao 'compromisso com a não-discriminação e promoção da equidade racial', o clube deve considerar a formação da sociedade brasileira e as persistentes desvantagens que caracterizam a situação da população negra (pretos e pardos) no país. Assim, o clube precisa dispor de uma política de promoção da equidade e não-discriminação racial formal e constante no código de conduta e/ou na declaração de valores do clube.

Por meio desse questionário é avaliado se o clube realiza campanhas internas de conscientização (seminários, fóruns ou encontros específicos) para melhorar a compreensão de seus empregados sobre a importância da equidade e não-discriminação racial ou se tem metas para promover a equidade racial nos processos de admissão, promoção e treinamento, em todos os níveis hierárquicos e em todas as áreas.

O indicador referente ao 'Compromisso com a promoção da equidade de gênero', avalia a 
cooperação do time em relação ao combate ao preconceito, a ampliação das chances das mulheres no mercado de trabalho e sua capacitação para funções especializadas. Assim, o clube deve promover uma política de promoção da equidade de gênero formal, devendo constar no código de conduta e/ou na declaração de valores do clube. Dessa política derivam procedimentos específicos para melhorar a qualificação das mulheres e promovê-las e proibição expressa da contratação, demissão ou promoção de mulheres baseada em seu estado civil ou condição reprodutiva além de explicitar a igualdade de condições para homens e mulheres no que se refere a salários e benefícios, previdência privada e acesso a treinamentos e bolsas de estudos.

O questionário também avalia se o clube realiza campanhas internas de conscientização para melhorar a compreensão de seus empregados sobre a importância da valorização da mulher, bem como se há plano de saúde do clube com adaptações específicas objetivando a manutenção e cuidados com a saúde da mulher ou se o clube tem metas de contratação, treinamento e mobilidade interna (horizontal e vertical) visando a promoção da equidade de gênero em todos os níveis hierárquicos e em todas as áreas.

A política de promoção da equidade deve garantir a participação feminina nos processos decisórios e na gestão, em todos os níveis hierárquicos e em todas as áreas do clube. Assim, também é avaliado se o clube promove, quando necessário, a adequação às condições físicas das mulheres de espaços de trabalho e de equipamentos, se o clube proíbe expressamente atividades que possam intimidar ou constranger as mulheres no ambiente de trabalho e se a promoção da equidade de gênero é uma das dimensões da política de comunicação entendida como uma estratégica do clube.

A política de comunicação comercial deve ter como premissa não utilizar a figura feminina de maneira estereotipada ou que atente contra a dignidade das mulheres. Nesse sentido, se faz necessário que o clube proíba expressamente a discriminação contra mulheres com problemas de saúde, inclusive as soropositivas e garante a proteção das mulheres contra a violência e o assédio psicológico, moral, físico e sexual no local de trabalho e na locomoção entre casa e empresa, bem como promova campanhas de sensibilização dos homens sobre a importância da divisão das tarefas domésticas e sobre a paternidade responsável.

No indicador referente as 'relações com trabalhadores terceirizados', o clube deve apresentar um código de conduta e/ou a declaração de valores do clube que contemple questões referentes à nãodiscriminação dos trabalhadores terceirizados, integrando-os a seus programas de treinamento e desenvolvimento profissional. Deve ser clara a conduta do clube ao possuir um número de trabalhadores terceirizados inferior a $20 \%$ (vinte por cento) do total de contratados e nessa política constar da integração dos trabalhadores terceirizados com a cultura, valores e princípios do clube.

No indicador sobre a 'política de remuneração, benefícios e carreira', o clube deve apresentar o plano de cargos e salários de forma transparente e ser abordado em seu código de conduta e/ou em sua declaração de valores e a remuneração variável do clube representa menos de $20 \%$ (vinte por cento) da massa salarial. O clube deve possuir políticas com metas para reduzir a distância entre a maior e a menor remuneração paga nos últimos dois anos, se aumentou o menor salário do clube em relação ao salário mínimo vigente e se 
realiza pesquisas para medir a satisfação dos empregados quanto à sua política de remuneração e benefícios.

O programa de participação nos resultados do clube, caso o possua, deve esclarecer se foi estabelecido por meio de negociação com uma comissão de empregados ou sindicato e em conformidade com a legislação aplicável. E se possuir um programa de bonificação do clube, deve esclarecer se foi estabelecido por meio de negociação com uma comissão de empregados ou sindicato e em conformidade com a legislação aplicável e se oferece aos empregados bônus adicionais orientados por elementos de sustentabilidade, como êxitos a médio e longo prazo ou o alcance de metas relacionadas ao desempenho social e ambiental.

No indicador referente aos 'cuidados com saúde, segurança e condições de trabalho' visam assegurar boas condições de trabalho, saúde e segurança, o clube precisa divulgar se foi certificada pela norma SA800031, pela BS 880032, pela OHSAS 1800133 ou por norma equivalente; se oferece programa de prevenção e tratamento para dependência de drogas e de álcool; se oferece programa específico para portadores de HIV/AIDS.

O código de conduta do clube deve possuir uma política de respeito à privacidade de seus empregados no que se refere a informações sensíveis (inclusive médicas) obtidas e mantidas sob responsabilidade da área de recursos humanos. Essa política deve prever a não-discriminação por HIV/AIDS com normas e processos para combater situações de assédio moral, os quais são divulgados e devidamente amparados por estrutura formal e neutra de denúncia e apuração de fatos.

Quanto às 'Políticas de conduta', o clube também precisa dispor de normas e processos para combater situações de assédio sexual, os quais são divulgados e devidamente amparados por estrutura formal e neutra de denúncia e apuração de fatos, promover exercícios físicos no horário de trabalho ou programa de combate ao estresse para os empregados, especialmente para os que desempenham funções mais estressantes.

É importante elencar também se o clube possui programa de orientação alimentar e nutricional, política de equilíbrio trabalho-família que aborde questões relativas a horário de trabalho e horas extras ou política de compensação de horas extras para todos os empregados, inclusive gerentes e executivos. No indicador referente ao 'Compromisso com o desenvolvimento profissional e a empregabilidade', para o desenvolvimento dos seus recursos humanos, o clube precisa dispor de informações se analisa periodicamente o perfil socioeconômico de seus empregados no sentido de balizar suas estratégias de remuneração e benefícios e de educação e desenvolvimento profissional, se mantém programa de erradicação do analfabetismo (absoluto e/ou funcional), educação básica ou ensino supletivo entre seus empregados, com metas e recursos definidos, se possui programa de mapeamento para identificação de competências potenciais a serem desenvolvidas, se contempla em suas políticas de desenvolvimento programas que promovam a coerência entre os valores e princípios éticos da organização com os valores e princípios individuais de seus empregados, se possui programas de aconselhamento sobre o planejamento de carreiras, de forma a auxiliar os empregados na reflexão sobre suas funções e identificação de objetivos em longo prazo, considerando seu papel social em relação aos estagiários, oferece a eles boas condições de 
trabalho, aprendizado e desenvolvimento profissional e pessoal em suas respectivas áreas de estudo, com o devido acompanhamento.

No indicador referente ao 'comportamento nas demissões para conduzir processos demissionais', o clube deve informar se teve reclamações trabalhistas relacionadas a demissão nos últimos três anos, se acompanha e avalia periodicamente a rotatividade de empregados e tem política para minimizar e melhorar esse indicador, se busca estabelecer diálogo estruturado com instâncias do governo local, especialistas, ONGs e sindicatos para conhecer, entender, prever e reduzir o impacto de um possível fechamento de unidades de negócios ou plantas, ou da eventual necessidade de corte de pessoal, se busca parcerias com organizações especializadas para desenvolver programas de capacitação e de estímulo ao empreendedorismo. E diante da alguma necessidade de redução de pessoal, se prevê uma comunicação dirigida aos empregados remanescentes sobre as razões que balizaram a decisão tomada

No indicador relacionado a 'preparação para a aposentadoria', o clube precisa informar se oferece programa de previdência complementar a todos os seus empregados, envolvendo familiares dos empregados no processo de preparação para a aposentadoria, se participa da elaboração de políticas públicas com foco em idosos ou se participa ou apoia programas e campanhas públicas ou privadas de valorização dos idosos.

\section{Dimensão meio ambiente}

Com relação a dimensão 'meio ambiente', está se divide em: responsabilidade com as gerações futuras e gerenciamento do impacto ambiental. Dentro do item 'responsabilidade com as futuras gerações' consta o indicador sobre o compromisso com a melhoria da qualidade ambiental, para tratar com a devida relevância e responsabilidade os impactos ambientais resultantes de suas atividades, o clube precisa informar sua política ambiental se é formal, de conhecimento de todos os empregados e consta no código de conduta e/ou na declaração de valores do clube.

É importante ter uma pessoa responsável pela área de meio ambiente que participa de suas decisões estratégicas e o clube deve participar de comitês/conselhos locais ou regionais para discutir a questão ambiental com o governo e a comunidade, contribuindo para a preservação da biodiversidade por meio de políticas específicas, projeto(s) de conservação de áreas protegidas e/ou programa de proteção a animais ameaçados

A política ambiental precisa ser explícita com a não-utilização de materiais e insumos provenientes de exploração ilegal de recursos naturais (como madeira, produtos florestais não-madeireiros, animais etc.) e dispor de processos para mapeamento e análise sistêmica para a melhoria da qualidade ambiental. No indicador sobre a 'educação e conscientização ambiental' visando contribuir para a conscientização da população quanto aos desafios ambientais decorrentes da atividade humana e cultivar valores de responsabilidade ambiental, o clube deve desenvolver periodicamente campanhas internas de redução do consumo de água e de energia, de educação com base nos 3 R's (reuso, reciclagem e redução) e de educação para o consumo consciente. 
No indicador que se refere ao 'gerenciamento dos impactos sobre o meio ambiente' e do ciclo de vida de produtos e serviços considerando os impactos ambientais causados por seus processos e produtos ou serviços, o clube deve apresentar se possui plano de emergência ambiental, que relaciona todos os seus processos e produtos ou serviços que envolvam situações de risco, e treina seus empregados regularmente para enfrentar tais situações, ou se possui política e sistema de monitoramento visando o aumento da qualidade ambiental da logística e gestão de frota, ou ainda, se possui programa de gerenciamento de resíduos com a participação do cliente, como para a coleta de materiais tóxicos ou a reciclagem pósconsumo.

Vale destacar a importância do fornecimento, aos consumidores e clientes, de informações detalhadas sobre danos ambientais resultantes do uso e da destinação final de seus produtos. $\mathrm{O}$ clube também precisa discutir com empregados, consumidores e clientes, fornecedores e a comunidade os impactos ambientais causados por seus produtos ou serviços e priorizar a contratação de fornecedores que comprovadamente tenham boa conduta ambiental, de preferência, com certificações ambientais, como a ISO14001, o selo FSC etc.

No indicador 'Sustentabilidade da Economia Florestal', o objetivo é contribuir com a conservação das florestas e combater sua exploração ilegal e predatória, bem como proteger a biodiversidade. Assim, o clube precisa realizar visitas programadas ou eventuais para realizar monitoramento da origem ou da cadeia de produção dos insumos madeireiros e florestais que utiliza, incentivar seus fornecedores a buscar a certificação florestal e priorizar e apoiar os fornecedores engajados na busca da sustentabilidade das florestas.

Já no indicador sobre a 'Minimização de entradas e saídas de materiais', o objetivo é prevenir e reduzir danos ambientais e otimizar processos. Assim, o clube deve possuir iniciativas para o uso de fontes de energia renovável, manter ações de controle da poluição causada por veículos próprios e de terceiros a seu serviço. É importante o clube possuir sistema de monitoramento com metas específicas para o aumento da eficiência energética, a redução do consumo de água, a redução da geração de resíduos sólidos, a redução da emissão de $\mathrm{CO}_{2}$ e outros gases do efeito estufa na atmosfera.

\section{Dimensão fornecedores}

Quanto a dimensão 'fornecedores', a avaliação se dá na seleção, avaliação e parceria com fornecedores através dos indicadores sobre critérios de seleção e avaliação de fornecedores, trabalho infantil na cadeia produtiva, trabalho forçado (ou análogo ao escravo) na cadeia produtiva e apoio ao desenvolvimento de fornecedores. Sobre os critérios de seleção e avaliação de fornecedores para regular suas relações com fornecedores e parceiros, o clube deve incluir as políticas e critérios para o relacionamento com os fornecedores em seu código de conduta e/ou em sua declaração de valores. Ao selecionar fornecedores (ou desenvolver novos fornecedores), o clube deve incluir como critério, a prática efetiva de processos éticos de gestão das informações de caráter privado obtidas em suas relações com clientes ou com o mercado em geral. Bem como possuir política explícita ou programa específico de responsabilidade social 
empresarial para a cadeia de fornecedores.

É importante também traduzir essas informações em números, assim o clube deve produzir relatório periódico com evidências de que questões relacionadas à responsabilidade social empresarial estão sendo cumpridas e implementadas em sua cadeia produtiva, discutindo questões relacionadas à responsabilidade social com seus fornecedores, visando o treinamento e adequação deles a seus critérios e estabelecendo prazos formais para que os fornecedores entrem em conformidade com seus critérios de responsabilidade social. Ao exigir práticas de responsabilidade social de seus fornecedores, realiza visitas de inspeção dessas práticas, conhece em profundidade a origem das matérias-primas, insumos e produtos utilizados em sua produção ou nas operações diárias e tem a garantia de que nessa origem os direitos humanos e o meio ambiente são respeitados e verifica se os mesmos adotam critérios de compra que consideram a garantia de origem, para evitar a aquisição de produtos piratas, falsificados ou frutos de roubo de carga.

No indicador sobre 'trabalho infantil na cadeia produtiva', são avaliadas as relações com fornecedores e parceiros. Para tanto, o clube precisa informar se tem como prática proceder periodicamente pesquisa, verificação e relatórios sobre sua cadeia produtiva, realizando inspeções in loco e exigindo documentação comprobatória da não-existência de mão-de-obra infantil.

No indicador relacionado ao 'trabalho forçado (ou análogo ao escravo) na cadeia produtiva', é avaliada as relações com fornecedores e parceiros. Nesse sentido, é preciso avaliar se o clube tem como prática proceder periodicamente pesquisa, verificação e relatórios de avaliação e acompanhamento de seus fornecedores, exigindo documentação comprobatória da não-existência de mão-de-obra forçada e se antes de comprar ou contratar um fornecedor, tem como procedimento verificar a lista suja de trabalho forçado do ministério do trabalho.

No indicador relacionado ao 'Apoio ao desenvolvimento de fornecedores', com relação a fornecedores de igual ou menor porte, o clube precisa relatar se inclui entre seus fornecedores indivíduos ou grupos da comunidade, tais como cooperativas de pequenos produtores ou de iniciativas solidárias, associações de bairro e organizações com projetos de geração de renda para grupos usualmente excluídos (populações indígenas, pessoas com deficiência etc.). Se apoia organizações que praticam e promovem o comércio Justo, se tem como norma o tratamento justo aos fornecedores, privilegiando o pequeno fornecedor (com remuneração justa e em dia, qualidade na relação, programas de qualificação e de transferência de tecnologia etc.) e se estimula a formação de redes ou cooperativas de pequenos fornecedores, ajudando-os a se adequar a novos padrões de fornecimento. $O$ clube também precisa fornecer informações se tem política de compras que privilegia fornecedores com certificação socioambiental, com mecanismos formais que permitem transferir para a cadeia de fornecedores seus valores e princípios, tais como boas condições de trabalho, ausência de trabalho infantil e forçado (ou análogo ao escravo), proteção ao meio ambiente, equidade de gênero, transparência, participação e prestação de contas e possui ouvidor de fornecedores ou função similar, para assegurar uma relação de parceria com eles. 


\section{Dimensão consumidores e clientes}

Na dimensão 'consumidores e clientes', a avaliação é dada na dimensão social do consumo com indicadores sobre política de comunicação comercial, excelência no atendimento e conhecimento e gerenciamento dos danos potenciais de produtos e serviços. No indicador eu se refere a 'política de comunicação comercial' é considerada a influência da política do clube em relação a comunicação comercial na criação de uma imagem de credibilidade e confiança. Assim, o clube deverá produzir uma política de comunicação comercial e esta deve estar no código de conduta e/ou na declaração de valores do clube. A política deve ter um caráter formal contra propaganda que coloque crianças, adolescentes, negros, mulheres ou qualquer indivíduo em situação preconceituosa, constrangedora, desrespeitosa ou de risco. Para isso, o clube deve realizar uma análise prévia de peças publicitárias para verificar a conformidade com seus valores e princípios e possuir políticas específicas para assegurar que a comunicação voltada para o público infantojuvenil seja responsável. O clube também deve interagir com seus fornecedores e distribuidores estimulando-os a adotar uma postura responsável em relação à comunicação voltada para o público infantojuvenil e realizar análise prévia de peças publicitárias para verificar a conformidade com a Declaração Universal dos Direitos Humanos.

Quanto ao indicador de 'excelência no atendimento' quanto a seu compromisso com a qualidade dos serviços de atendimento ao consumidor/cliente, o clube precisa adotar uma política e as normas de relacionamento com clientes e consumidores que esteja contida no código de conduta e/ou na declaração de valores do clube. Para tanto o clube deve possuir um ouvidor do consumidor ou função similar, oferecer serviço de atendimento ao cliente (SAC) ou outra forma de atendimento especializado para receber e encaminhar sugestões, opiniões e reclamações relativas a seus produtos e serviços, promover treinamento contínuo de seus profissionais de atendimento para uma relação ética e de respeito aos direitos do consumidor, treinar e incentivar seu profissional de atendimento a reconhecer falhas e agir com rapidez e autonomia na resolução de problemas e, principalmente, advertir continuamente seu profissional de atendimento e áreas correlatas sobre a importância de procedimentos éticos na obtenção, manutenção e uso das informações de caráter privado resultantes da interação com seus consumidores, clientes ou usuários.

O serviço de atendimento a consumidores/clientes precisa ser acompanhado por indicadores e tem representação nos processos de tomada de decisão do clube. Ao vender produtos e serviços, o clube deve utilizar somente argumentos verdadeiros para o convencimento do consumidor ou cliente e esse posicionamento deve estar de acordo com a política que precisa ser explícita de não-suborno para obtenção de decisão de compra de produtos ou contratação de serviços. Outra questão relevante é o fato do clube ter de possuir uma política formal de proteção à privacidade e/ou um sistema de gestão das informações privadas do consumidor, cliente ou usuário que informe ao cliente o propósito da coleta de informações pessoais antes de fazê-la fornecendo informações cadastrais do cliente a terceiros apenas mediante a autorização dele, permitindo ao consumidor, cliente ou usuário a inclusão, alteração e exclusão de seus 
dados do banco de informações do clube.

Quanto ao indicador de 'Conhecimento e gerenciamento dos danos potenciais dos produtos e serviços', o clube deve manter um programa especial com foco em saúde e segurança do consumidor/cliente de seus produtos e serviços, possuir sistemas internos ágeis e capacitar sua área de comunicação externa para responder com rapidez e transparência a situações de crise.

\section{Dimensão comunidade}

Na dimensão 'Comunidade' se trabalha com as relações com a comunidade local avaliando o gerenciamento do impacto do clube na comunidade de entorno e as relações com organizações locais e com o item ação social avaliando o financiamento da ação social e o envolvimento com a ação social. No indicador sobre o 'gerenciamento do impacto do clube na comunidade de entorno' é considerado seus possíveis impactos na vida da comunidade (demanda sobre centros de saúde e lazer, creches, transporte público, tráfego de veículos etc.). Assim, o clube deve reconhecer a comunidade em que está presente como parte interessada importante em seus processos decisórios, possuir políticas de relacionamento com a comunidade de entorno contempladas em seu código de conduta e/ou na declaração de valores, participar ativamente da discussão de problemas comunitários e do encaminhamento de soluções, contribuir com melhorias na infraestrutura ou no ambiente local que possam ser usufruídas pela comunidade (habitações, estradas, pontes, escolas, hospitais etc.), e ter programa para empregar, na medida do possível, o maior número de moradores do local em que está inserida, dando-Ihes formação, com o objetivo de aumentar os níveis de qualificação daquela comunidade, em cooperação com sindicatos, ONGs, representantes da comunidade ou autoridades públicas competentes.

Também é importante, em relação a esse item o clube enfatizar práticas de compras e de investimentos para aprimorar o desenvolvimento socioeconômico da comunidade em que está presente, conscientizando e treinando seus empregados para respeitar os valores, conhecimento e práticas tradicionais da comunidade em que atua.

Com relação ao indicador de 'Relações com organizações locais', o clube precisa fazer um levantamento das necessidades locais antes de desenhar seus projetos na comunidade, bem como mostrar que realiza na comunidade, em conjunto com organizações locais, campanhas educacionais e/ou de interesse público. Com relação ao indicador de 'financiamento da ação social' é baseado em informações se o clube inclui a ação social e seus responsáveis no processo geral de planejamento estratégico, possui mecanismos para estimular fornecedores, acionistas e outras partes interessadas a fazer doações financeiras, utiliza especialistas no ciclo de planejamento, monitoramento e avaliação de sua ação social, planeja sua ação social visando maximizar seu impacto a longo prazo, otimiza o impacto da sua ação social alavancando recursos de outras empresas ou organizações privadas e/ou a participação de órgãos públicos e se tem procedimento de consulta periódica aos beneficiários de sua ação social, monitorando-a por meio de indicadores de desempenho.

Já o indicador de 'envolvimento com a ação social', entendido como forma de concretizar sua ação 
social, o clube irá ser avaliado se utiliza os incentivos fiscais para deduzir ou descontar dos impostos os valores relativos a doações e patrocínios, divulga internamente os projetos que apoia e desenvolve, oferecendo oportunidades de trabalho voluntário e estimulando a participação dos empregados. Bem como se autoriza o uso controlado de horas pagas para o trabalho voluntário de empregados. Quanto à 'governança da ação social', o clube precisa destacar se possui um conselho ou comitê misto, com membros de diferentes áreas do clube ou do grupo empresarial, incluindo membros da sociedade credenciados para tratar da área temática em que atua.

\section{Dimensão governo e sociedade}

Na dimensão 'governo e sociedade', são avaliados a transparência política (contribuições para campanhas políticas, construção da cidadania pelas empresas indicador e práticas anticorrupção e antipropina) e liderança social (liderança e influência social e participação em projetos sociais governamentais).

Com relação ao indicador 'Contribuições para campanhas políticas' o clube precisa fornecer informações relacionadas aos últimos cinco anos, se o mesmo foi mencionado negativamente na imprensa por contribuir financeiramente para campanha política e se tem norma explícita de não utilização do poder econômico para influenciar contribuições de outras empresas, fornecedores, distribuidores e outros parceiros.

No indicador 'Construção da cidadania' pelos clubes é avaliado o seu papel na construção da cidadania. Assim, deve ser avaliado se o clube estimula seus empregados a avaliar e controlar a atuação dos eleitos. Já no indicador 'Práticas anticorrupção e antipropina', é avaliado relacionamento com autoridades, agentes e fiscais do poder público, em todos os níveis. Assim o clube precisa comprovar se teve seu nome mencionado na imprensa nos últimos cinco anos sob suspeita de ter participado de incidente envolvendo o oferecimento de propina ou a prática de corrupção de agentes públicos. E precisa comprovar se pratica ações quem preveem medidas punitivas aos empregados envolvidos no favorecimento a agentes do poder público através de uma política explícita de não apoio e não participação em processos que objetivem a manipulação de editais de concorrência (públicos ou privados).

No indicador de 'Liderança e influência social', é analisado segundo o modelo ETHOS a busca do exercício da cidadania por meio de associações e fóruns empresariais. Assim, o clube precisa comprovar que patrocina ou realiza campanhas de mídia exclusivamente relacionadas a questões de interesse público, se interage ativamente com instituições de ensino de todos os níveis a fim de elaborar propostas para melhorar a qualificação da mão-de-obra do setor em que atua e se estimula e patrocina projetos de desenvolvimento de pesquisa e tecnologia, interagindo ativamente com a comunidade acadêmica e científica.

No indicador de 'Participação em projetos sociais governamentais' se analisa o envolvimento do clube com as atividades sociais realizadas por entidades governamentais. Assim, o clube deve demonstrar que adota ou desenvolve parceria com organismos públicos visando objetivos como melhorar a qualidade de ensino, a assistência social, a saúde ou a infraestrutura, erradicar o trabalho infantil e/ou o trabalho 
forçado, incentivar a geração de renda e/ou de emprego, promover segurança alimentar etc.. Também deve demonstrar se patrocina programa público ou privado de bolsa escolar e se articula e coordena parcerias nos programas de que participa.

\section{CONCLUSÕES}

Diante do detalhamento histórico da evolução das várias visões a respeito das concepções e adequação das teorias relacionadas à RS, foi possível compreender que o discurso está de fato em conformidade com o relacionamento recíproco entre as atividades principais da organização com as carências prementes da sociedade, de maneira que as ações neste sentido ocasionem reflexos positivos, seja para os negócios, como também para o desenvolvimento comunitário.

É por meio da bandeira da efetividade que a RS encontra seu caminho mais decisivo nos processos das organizações, já que visa buscar aproximação com seus diversos stakeholders e, portanto, relacionar-se, em uma lógica de mercado. A analogia que se pode fazer passa pela compreensão do impacto social de determinada instituição, isto é, tudo o que ela faz em prol do social e aquilo que ela poderia fazer por si própria.

Além de um melhor relacionamento com os stakeholders, as ações de RS são capazes de evitar o aumento da fiscalização e regulação, contempla mudanças no formato da demanda entre os mercados de consumo e; adapta critérios de investimento nos mercados global. Tal avanço deve estar embasado na inovação e modernização da gestão de instituições - não raras as vezes, centenárias - e a questão da RSC adequa-se bem neste contexto.

Possuir no mercado métodos que fortaleçam práticas éticas, transparentes e de gestão democrática e estratégica permite que empresas avancem em gestão, conduta ética, respeito frente aos stakeholders e, principalmente, na melhoria financeira. O método instituído pelo Instituto ETHOS, reflete quatro dimensões que são subdivididas em 40 indicadores que demonstraram com riqueza de detalhes uma postura proba de qualquer empresa, em especial do Santa Cruz Futebol Clube. A troca de valores entre o clube e os indivíduos aparenta ser de fato o fator preponderante para que práticas nesta esfera obtenham um impacto perene, ou seja, estejam introduzidas na visão atual de governança estratégica de forma definitiva, e não apenas eventualmente. Pode-se concluir, portanto que a adoção de Responsabilidade Social Corporativa pode influenciar de forma significativa e expressiva o clube e os stakeholders associados ao Santa Cruz Futebol Clube.

\section{REFERÊNCIAS}

CAETANO, D. S. G.. Responsabilidade social corporativa e marketing social dos clubes de futebol: uma aplicação a casos espanhóis de referência internacional. Dissertação (Mestrado em Marketing) - Universidade da Beira Interior, Covilhã, 2008.

CERVO, A. L.; BERVIAN, P. A.. A metodologia científica. 3 ed. São Paulo: McGraw-Hill, 1996.
DANTAS, M. G. S.; BOENTE, D. R.. A eficiência financeira e esportiva dos maiores clubes de futebol europeus utilizando a análise envoltória de dados. Revista de Contabilidade e Organizações, v. 5, n. 13, p. 75-90. 2011.

DOH, J. E.; GUAY, T.. Corporate Social Responsibility, Public Policy, and NGO Activism in Europe and the United States: Na Institutional-Stakeholder Perpective. Working Paper, Journal of Mamagement Studies, v.43, p.47-73. 2006. 
FERNANDES, L. F. F.. A gestão dos clubes de Futebol como clube empresa: estratégias de negócio. Dissertação (Mestrado em Administração) - Universidade Federal do Rio Grande do Sul, 2000

GIL, A. C.. Como elaborar projetos. São Paulo: Atlas, 2001.

MÁXIMO, J.; KAZ, L.. Brasil: um século de futebol arte e magia. Rio de Janeiro: Aprazível, 2006.

PERRUCI, F. F.. Clube-empresa: o modelo brasileiro para transformação dos clubes de futebol em sociedades empresárias. Dissertação (Mestrado em Direito) - Faculdade de Direito Milton Campos, 2006.
RABELO, N. S.; SILVA, C. E.. Modelos de indicadores de responsabilidade socioambiental corporativa. Revista Brasileira de Administração Científica, Aquidabã, v.2, n.1, p.5-30, 2011.

SILVA, E.; MINCIOTTI, S.. A Aplicação do Marketing Social ao Planejamento, Elaboração e Implementação de Políticas Públicas de Saúde: Uma avaliação do que ocorre em São Caetano do Sul (SP). Working Paper, São Paulo, 2005.

VAN MARREWIJK, M.. Concepts and Definitions of CSR and Corporate Sustainability: Between Agency and Communion Journal of Business Ethics, v.44, n.2-3, p.95-105, 2003.

A CBPC - Companhia Brasileira de Produção Científica (CNPJ: 11.221.422/0001-03) detém os direitos materiais desta publicação. Os direitos referem-se à publicação do trabalho em qualquer parte do mundo, incluindo os direitos às renovações, expansões e disseminações da contribuição, bem como outros direitos subsidiários. Todos os trabalhos publicados eletronicamente poderão posteriormente ser publicados em coletâneas impressas sob coordenação da Sustenere Publishing, da Companhia Brasileira de Produção Científica e seus parceiros autorizados. Os (as) autores (as) preservam os direitos autorais, mas não têm permissão para a publicação da contribuição em outro meio, impresso ou digital, em português ou em tradução. 